\title{
Regular, sustained-release morphine for chronic breathlessness: a multicentre, double-blind, randomised, placebo-controlled trial
}

\author{
David Currow (1) 1,2 Sandra Louw, ${ }^{3}$ Philip McCloud, ${ }^{3}$ Belinda Fazekas, ${ }^{1,2}$ \\ John Plummer, ${ }^{2}$ Christine F McDonald, ${ }^{4,5}$ Meera Agar, ${ }^{1}$ Katherine Clark, ${ }_{1}^{6,7}$ \\ Nikki McCaffery, ${ }^{2,8}$ Magnus Pär Ekström, ${ }^{1,9}$ On behalf of the Australian National \\ Palliative Care Clinical Studies Collaborative (PaCCSC)
}

\begin{abstract}
- Additional material is published online only. To view, please visit the journal online (http://dx.doi.org/10.1136/ thoraxinl-2019-213681).
\end{abstract}

For numbered affiliations see end of article.

Correspondence to Professor David Currow, Faculty of Heath, University of Technology Sydney, Sydney, NSW 2007, Australia; david.currow@uts.edu.au

Received 5 June 2019 Revised 8 August 2019 Accepted 20 August 2019 Published Online First 26 September 2019

\section{Linked}

http://dx.doi.org/10.1136/ thoraxjnl-2019-214008

\section{Check for updates}

(C) Author(s) (or their employer(s)) 2020. No commercial re-use. See rights and permissions. Published by BMJ.

To cite: Currow D, Louw S, McCloud $\mathrm{P}$, et al. Thorax

2020;75:50-56.

\begin{abstract}
Introduction Morphine may decrease the intensity of chronic breathlessness but data from a large randomised controlled trial (RCT) are lacking. This first, large, parallel-group trial aimed to test the efficacy and safety of regular, low-dose, sustained-release (SR) morphine compared with placebo for chronic breathlessness.

Methods Multisite (14 inpatient and outpatient cardiorespiratory and palliative care services in Australia), parallel-arm, double-blind RCT. Adults with chronic breathlessness (modified Medical Research Council $\geq 2$ ) were randomised to $20 \mathrm{mg}$ daily oral SR morphine and laxative (intervention) or placebo and placebo laxative (control) for 7 days. Both groups could take $\leq 6$ doses of $2.5 \mathrm{mg}$, 'as needed', immediate-release morphine ( $\leq 15 \mathrm{mg} / 24$ hours) as required by the ethics review board. The primary endpoint was change from baseline in intensity of breathlessness now (0-100 mm visual analogue scale; two times per day diary) between groups. Secondary endpoints included: worst, best and average breathlessness; unpleasantness of breathlessness now, fatigue; quality of life; function; and harms.
\end{abstract}

Results Analysed by intention-to-treat, 284 participants were randomised to morphine $(n=145)$ or placebo $(n=139)$. There was no difference between arms for the primary endpoint (mean difference $-0.15 \mathrm{~mm}(95 \% \mathrm{Cl}$ -4.59 to $4.29 ; p=0.95))$, nor secondary endpoints. The placebo group used more doses of oral morphine solution during the treatment period (mean 8.7 vs 5.8 doses; $p=0.001$ ). The morphine group had more constipation and nausea/vomiting. There were no cases of respiratory depression nor obtundation.

Conclusion No differences were observed between arms for breathlessness, but the intervention arm used less rescue immediate-release morphine.

Trial registration number ACTRN12609000806268.

\section{INTRODUCTION}

Breathlessness at rest or on minimal exertion is prevalent in people with advanced disease and at the end of life. ${ }^{1-3}$ Disabling breathlessness often persists despite optimal therapies for the underlying pathologies ${ }^{4}$ and is associated with increased anxiety and depression, ${ }^{56}$ impaired function, ${ }^{6}$ poorer quality of life, ${ }^{7}$ increased health service utilisation ${ }^{8}$ and earlier death. ${ }^{9}$ Chronic

\section{Key messages}

What is the key question?

- Does regular, low-dose, sustained-release morphine provide a better reduction in breathlessness now than placebo in people with moderate-to-severe chronic breathlessness?

What is the bottom line?

- There was no difference between arms in reduction of breathlessness now between the placebo and the intervention arm at 1 week.

Why read on?

- This multisite study is larger than the cohorts assembled in the recent meta-analyses that have explored this question. Given the unrelieved symptom burden experienced by millions of people daily globally, it is imperative to find methods of reducing the symptomatic burden of chronic debilitating breathlessness.

breathlessness causes considerable distress for patients, caregivers and healthcare providers. ${ }^{10} 11$

Until 2019, there had been no registered pharmacological treatment for the symptomatic reduction of chronic breathlessness. ${ }^{5} 12$ Two meta-analyses of mostly small, crossover trials reported promising results for regular, low-dose, systemic opioids. ${ }^{13-15}$ Most evidence pertains to patients with COPD and the use of oral sustained-release (SR) morphine. ${ }^{15} \mathrm{~A}$ pooled analysis found that people with more severe breathlessness were more likely to benefit from morphine. $^{16}$

Treatment with regular, low-dose, systemic opioids is recommended by several international consensus statements for palliating severe chronic breathlessness in advanced disease. ${ }^{17-21}$ However, the optimal treatment of symptomatic chronic breathlessness needs further research, as studies were relatively small with limited standardised assessments of adverse events. ${ }^{13} 1522$ A particular concern for many clinicians is the potential risk that even low-dose opioids may cause respiratory depression, especially in people with severe illness. Associations between opioids and adverse outcomes 


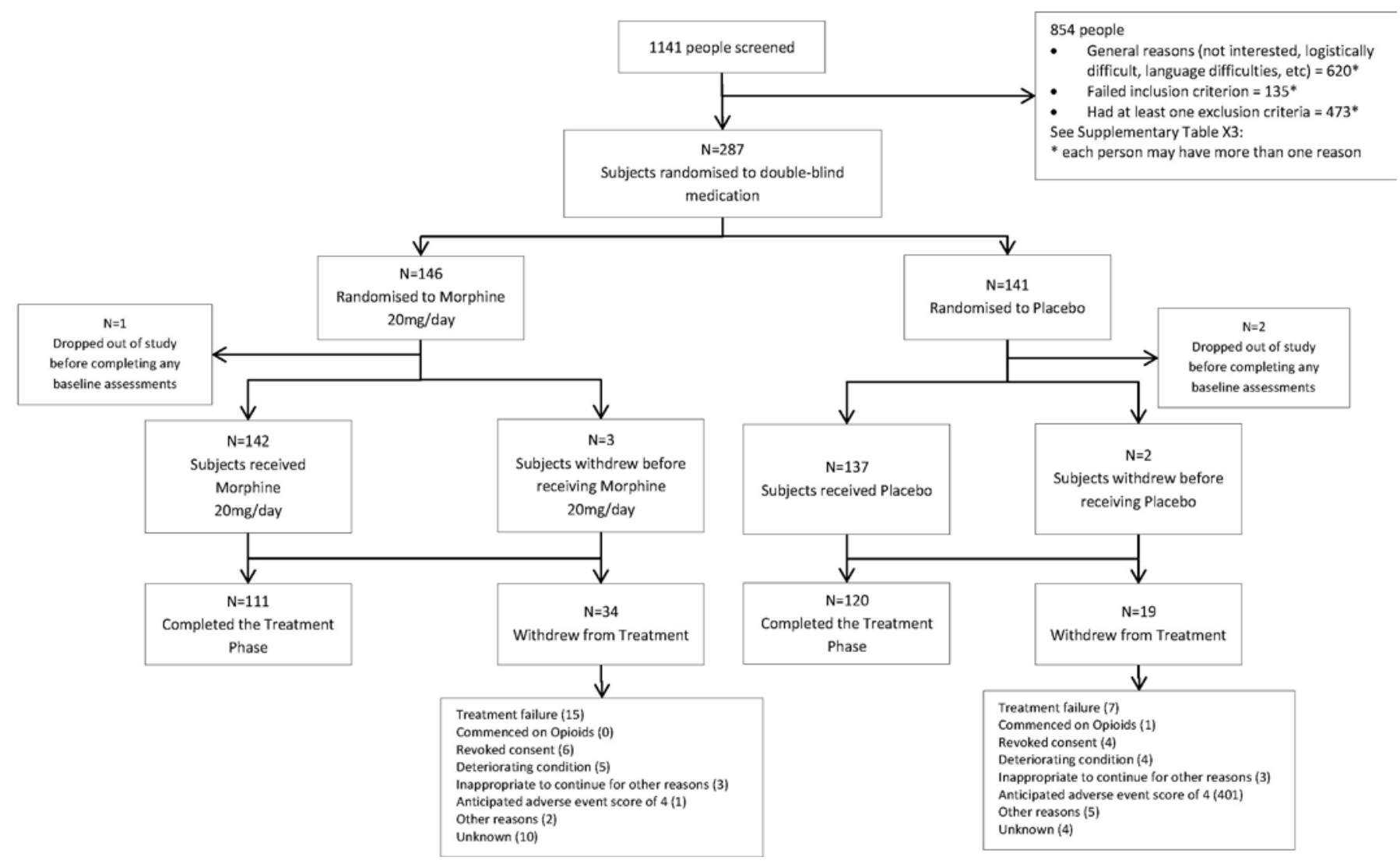

Figure 1 CONSORT diagram.

have been conflicting in retrospective observational studies, ${ }^{23-25}$ whereas serious adverse events have not been reported in the previous randomised controlled trials (RCTs). ${ }^{15} 23$ A large, pragmatic, parallel-arm, RCT was needed to evaluate the clinical effectiveness and safety of regular, low-dose, systemic SR morphine, and to explore patient groups more likely to derive net benefit.

The primary aim of the present study was to determine the efficacy and safety of regular, low-dose, once daily, oral SR morphine compared with placebo for chronic breathlessness over 1 week in patients with severe disease.

\section{METHODS}

\section{Study design and amendment}

This was a phase III, multicentre, double-blind, randomised (1:1), parallel-arm trial of daily $20 \mathrm{mg}$ oral SR morphine compared with placebo for 7 days. The trial was conducted and monitored in accordance with Good Clinical Practice (GCP). ${ }^{26}$ An independent Data Safety Monitoring Committee reviewed all adverse event reports and conducted a prespecified, blinded interim analysis after $50 \%$ of planned completions to confirm baseline sample size estimates.

This trial initially included a third randomisation group (controlled-release oxycodone $5 \mathrm{mg}$ PO three times a day) and required participants to have a modified Medical Research Council (mMRC) breathlessness score ${ }^{27}$ of $\geq 3$ to be included (figure 1). On 22 July 2014, due to insufficient recruitment (241 participants: oxycodone 74, morphine 86 and placebo 81 ) to meet the funded study timeframe for the primary comparison of morphine versus placebo, the trial was amended in consultation with the Trials Management Committee overseeing the study and approved by the Human Research Ethics Committee. Two changes were made: (1) mMRC eligibility criterion was changed from $\geq 3$ to $\geq 2$ and (2) the oxycodone randomisation group was deleted from the protocol and participants randomised to the morphine and placebo groups were retained in the present study. Trial registration was updated accordingly.

\section{Study population}

Participants were recruited from 14 respiratory and palliative care services across Australia's National Palliative Care Clinical Studies Collaborative.

Inclusion criteria were: age $\geq 18$ years; chronic breathlessness defined as an $\mathrm{mMRC}^{27}$ breathlessness score, initially $\geq 3$ (February 2010 to July 2014) and then $\geq 2$ at screening despite optimal management of underlying cause(s) of breathlessness as certified by the participant's treating physician; stable medications for breathlessness for the previous week except 'as needed' medications; the ability to speak and read English (fifth grade level); and expected survival of $\geq 2$ months in the opinion of the treating physician.

Exclusion criteria were: treatment with $\geq 20 \mathrm{mg}$ oral morphine equivalent per day in the 7 days before screening; Australia-modified Karnofsky Performance Status (AKPS) scale $<40^{28}$; uncontrolled nausea, vomiting or gastrointestinal obstruction; calculated creatinine clearance $<25 \mathrm{~mL} / \mathrm{min}^{29}$; two or more hepatic enzymes $\geq 3$ times the upper limit of normal or international normalised ratio $>1.2$ when not on warfarin; unresolved respiratory or cardiac event in the previous week (excluding upper respiratory tract infections); resting respiratory rate $\leq 8 \mathrm{~min}^{-1}$; history of opioid-related respiratory failure; anaemia for which a blood transfusion was indicated for breathlessness; inability to give informed consent or complete diary entries; or being pregnant or breastfeeding. 


\section{Randomisation and interventions}

Participants were randomised (1:1) to a daily opaque capsule of $20 \mathrm{mg}$ of oral morning SR morphine and two daily capsules of blinded laxative (docusate with sennosides), or similarly appearing placebo and placebo laxative capsules, for 7 days. Randomisation sequence was by blocks of four to ensure similar numbers of participants in each arm with stratification by site and dominant cause of breathlessness (COPD, cancer, end-stage cardiac failure, mixed or other). Additional open-label laxatives were available to all participants.

An SR morphine preparation was chosen because this delivers lower peaks and higher troughs ${ }^{30}$ compared with immediaterelease oral morphine solution. A fixed dose of $20 \mathrm{mg}$ was chosen as it was safely used in a previous crossover $\mathrm{RCT}^{14}$ and a longitudinal clinical trial with longer follow-up (mean 142 days (SD 190); median 29 days (range 2-660)). ${ }^{31}$

The Human Research Ethics Committee required that all participants could take up to six, 'as needed', doses of immediaterelease oral morphine solution $2.5 \mathrm{mg}$ per dose per 24 hours.

\section{Assessments}

Participants completed a diary on each of the seven treatment days documenting the intensity and unpleasantness of breathlessness now (morning and evening diary), and the worst, best and average breathlessness intensity over the previous 24 hours (evening diary). Breathlessness was self-reported on a $0-100 \mathrm{~mm}$ horizontal visual analogue scale (VAS) anchored between 0 ('none') and 100 ('worst possible' for intensity or 'the most unpleasant I have ever felt' for unpleasantness).

Assessments at baseline and end of treatment included measurements of participants' quality of life using the European Organization for Research and Treatment of Cancer-Quality of Life Questionnaire Core 15 PAL (EORTC-QLQ-C15 PAL; higher score reflects poorer quality of life $)^{32}$; carers' quality of life using Carer Quality of Life Index-Cancer (CQOLC; higher scores reflecting better quality of life $)^{33}$; and, at study end only, blinded participants' preferences to continue the assigned treatment group and global impression of change in overall health status from baseline.

Safety measures included oxygen saturation and end-tidal carbon dioxide $\left(\mathrm{CO}_{2}\right)$ measurement (Lifesense Monitor, Nonin Medical, Plymouth, Massachusetts, USA) at each contact, and Australiamodified Karnofsky Performance Scale (AKPS) weekly. ${ }^{28}$

Adverse events and vital status were assessed by the study staff at each contact. Assessment at baseline, during the mid-treatment week telephone call and during the weekly telephone calls, which occurred for 4 weeks after the end of treatment, used the National Institutes of Health Common Terminology Criteria for Adverse Events V.4.0. ${ }^{34}$ Treatment emergent adverse events (TEAE) were defined as symptoms that appeared or worsened after baseline. The diary specifically sought symptoms that may be associated with morphine, including anxiety, appetite, concentration, confusion, constipation, nausea or vomiting, sleepiness and well-being, assessed using Likert scales. Use of 'as needed' morphine was recorded by participants in the evening diary.

\section{Endpoints}

The primary endpoint was change in intensity of breathlessness now ('How is your breathlessness right now?'; $100 \mathrm{~mm}$ VAS) from baseline to the average of the morning and evening scores of days $5-7 . .^{35}$ This endpoint has been validated and was used in previous morphine RCTs. ${ }^{14}{ }^{15}$ An average of the last 3 days was chosen to ensure assessment at steady state of the treatment, and to minimise the influence of symptom fluctuations and missing data in this population with advanced disease.

Secondary endpoints were intensity of worst, best and average breathlessness in the previous 24 hours and unpleasantness of breathlessness now, participant health-related quality of life (EORTC-QLQ-C15 PAL overall and sub-domains), caregiver quality of life (CQOLC), participant treatment preference and use of 'as needed' morphine. Safety endpoints included changes in end-tidal $\mathrm{CO}_{2}$, changes in functional status (AKPS), respiratory depression, confusion or obtundation and survival rate after first study drug.

\section{Sample size}

A sample size of 235 participants with data provided $80 \%$ power to detect a clinically meaningful difference of $8.9 \mathrm{~mm}^{36}$ between groups in the primary endpoint, assuming a SD of $22 \mathrm{~mm}$ on the $100 \mathrm{~mm}$ VAS based on a previous study,${ }^{14}$ and a significance level of 0.05 using a two-tailed test.

\section{Statistical analysis}

All efficacy analyses were on an intention-to-treat (ITT) basis, which excluded three people randomised who did not complete any baseline or post-baseline data. The multiple imputation (MI) analyses were conducted using all ITT patients with at least one breathlessness result in the patient diary.

The primary and secondary endpoints were compared between groups using analysis of covariance, with change from baseline to the mean score of days 5-7 as the dependent variable. Independent variables were the allocated treatment group, stratification factors (study site, baseline dominant cause of breathlessness and an interaction term between these) and the baseline breathlessness score. Response was defined as an absolute difference of at least $8.9 \mathrm{~mm}$ in breathlessness from baseline to the mean of days $5-7 .{ }^{16}$ Response was analysed using logistic regression with the same independent variables, with estimates expressed as OR. Missing values for the primary, secondary and subgroup analyses of breathlessness were imputed using Markov Chain Monte Carlo MI with 50 samples redrawn. Safety analyses included all participants who received at least one dose of study medication. Subgroup analyses were conducted in people with mMRC score 3 or 4 (the original study population). ${ }^{16}$

All estimates were presented with 95\% CIs. P values were two-sided with the level of statistical significance set to 0.05 . Secondary endpoints were exploratory and $p$ values were not adjusted for multiple comparisons. All secondary analyses apart from the breathlessness analyses were conducted on the data as observed with no imputation for missing values. Analyses were performed with SAS V.9.4. This study is reported in compliance with the CONSORT statement for reporting RCTs.

\section{Ethics and registration}

All subjects gave their informed written consent prior to participation. Part of the database was used for a published observational comparison of breathlessness intensity and severity. ${ }^{35}$

\section{RESULTS}

Between February 2010 and July 2015, 1141 people were screened (online supplementary figure S1 and table S4) and 287 participants at 14 centres were randomised to either SR morphine $20 \mathrm{mg} /$ day $(n=146)$ or placebo $(n=141$; figure 1$)$. Three participants did not provide any diary data and were excluded from the analysis. The 284 included participants had a mean age of 74.3 years (SD 9.33 years); 180 (63\%) were male; 
Table 1 Baseline characteristics of participants in a multisite, placebo-controlled, parallel-arm study of $20 \mathrm{mg}$ morphine daily for chronic breathlessness

\begin{tabular}{|c|c|c|c|}
\hline & \multicolumn{2}{|c|}{$\begin{array}{l}\text { Intention-to-treat-whole } \\
\text { population }\end{array}$} \\
\hline & & $\begin{array}{l}\text { Morphine } \\
(n=145)\end{array}$ & $\begin{array}{l}\text { Placebo } \\
(n=139)\end{array}$ \\
\hline \multirow[t]{2}{*}{ Age (years) } & Mean (SD) & $74.0(9.6)$ & $74.5(9.1)$ \\
\hline & Min, $\max$ & $44.8,94.1$ & $44.3,89.4$ \\
\hline Gender, n (\%) & Female & $52(35.9 \%)$ & $52(37.4 \%)$ \\
\hline \multirow[t]{2}{*}{ Performance status (AKPS) } & Mean (SD) & 60.8 (11.5) & $61.5(9.5)$ \\
\hline & Min, $\max$ & 3,90 & 40,80 \\
\hline \multirow[t]{2}{*}{ BMI $\left(\mathrm{kg} / \mathrm{m}^{2}\right)$} & Mean (SD) & $25.2(7.6)$ & $25.9(7.0)$ \\
\hline & Min, $\max$ & $13.0,66.1$ & $12.3,47.8$ \\
\hline \multirow{4}{*}{$\begin{array}{l}\text { mMRC breathlessness now score } \\
\text { at baseline, } \mathrm{n}(\%)\end{array}$} & 1 & $18(14.1 \%)$ & $12(10.3 \%)$ \\
\hline & 2 & $22(17.2 \%)$ & $25(21.6 \%)$ \\
\hline & 3 & $33(25.8 \%)$ & 33 (28.4\%) \\
\hline & 4 & 55 (43.0\%) & 46 (39.7\%) \\
\hline \multirow{4}{*}{$\begin{array}{l}\text { Baseline mean (SD) } \\
\text { breathlessness scores (0-100 mm } \\
\text { visual analogue scale) }\end{array}$} & Now & $40.9(22.0)$ & $42.9(23.1)$ \\
\hline & Worst & $58.5(23.8)$ & $60.7(24.9)$ \\
\hline & Best & $28.3(21.3)$ & $30.1(20.5)$ \\
\hline & Average & $41.2(18.5)$ & $43.8(20.6)$ \\
\hline \multirow[t]{2}{*}{ Charlson Comorbidity Index } & Mean (SD) & $3.3(2.46)$ & $3.2(2.5)$ \\
\hline & Min, $\max$ & 0,12 & 1,13 \\
\hline \multirow[t]{2}{*}{ Pulse oximetry $\mathrm{SpO}_{2}(\%)$} & Mean (SD) & $92.60(4.17)$ & $92.96(4.46)$ \\
\hline & Min, max & $77.0,99.0$ & $72.0,99.0$ \\
\hline \multirow[t]{2}{*}{ End-tidal $\mathrm{CO}_{2}(\mathrm{~mm} \mathrm{Hg})$} & Mean (SD) & $27.41(8.29)$ & $25.53(6.98)$ \\
\hline & Min, $\max$ & $8.5,53.1$ & $9.9,45.0$ \\
\hline \multirow{5}{*}{$\begin{array}{l}\text { Primary cause for breathlessness, } \\
\mathrm{n}(\%)\end{array}$} & COPD & $82(56.6 \%)$ & $82(59.0 \%)$ \\
\hline & Cancer & $26(17.9 \%)$ & $22(15.8 \%)$ \\
\hline & $\begin{array}{l}\text { Cardiac } \\
\text { failure }\end{array}$ & $2(1.4 \%)$ & $2(1.4 \%)$ \\
\hline & Mixed & $18(12.4 \%)$ & $19(13.7 \%)$ \\
\hline & Other & $17(11.7 \%)$ & $14(10.1 \%)$ \\
\hline Oxygen use & Yes, n (\%) & $87(60.0 \%)$ & $75(54.0 \%)$ \\
\hline \multirow[t]{4}{*}{ Smoking status, n (\%) } & $\begin{array}{l}\text { Never } \\
\text { smoked }\end{array}$ & $24(16.6 \%)$ & $26(18.7 \%)$ \\
\hline & Ex-smoker & $104(71.7 \%)$ & $95(68.3 \%)$ \\
\hline & $\begin{array}{l}\text { Current } \\
\text { smoker }\end{array}$ & $17(11.7 \%)$ & $16(11.5 \%)$ \\
\hline & Missing & $0(0.00 \%)$ & $2(1.4 \%)$ \\
\hline
\end{tabular}

AKPS, Australia-modified Karnofsky Performance Status; BMI, body mass index; $\mathrm{CO}_{2}$, carbon dioxide; mMRC, modified Medical Research Council.

164 (58\%) had COPD; and 167 (59\%) had an mMRC score of 3 or 4 at baseline (table 1). The proportion of participants completing the 7-day treatment period was lower for morphine $(111 / 145 ; 77 \%)$ than placebo $(120 / 139 ; 86 \%$; figure 1$)$.

\section{Efficacy endpoints}

There was no clinically or statistically significant difference between treatment groups for the primary endpoint of breathlessness now (mean difference $-0.15 \mathrm{~mm}$; $95 \% \mathrm{CI}-4.59$ to $0.29 ; \mathrm{p}=0.95$; table 2 ). There were no clinically or statistically significant between-group differences for any of the secondary breathlessness efficacy endpoints (table 2).

\section{Rescue medication use}

The mean number of doses of immediate-release oral morphine solution taken during the study was 55\% higher in the placebo group $(8.7 ; 95 \%$ CI 7.1 to 10.6$)$ than in the morphine group (5.8; $95 \%$ CI 4.4 to 7.2$)$; a mean 0.56 (95\% CI 0.18 to 0.92 ; $\mathrm{p}=0.003)$ more doses per day of rescue morphine in the placebo group.

\section{Safety}

The number of participants with one or more adverse event of special interest during the study was similar between treatment groups (table 3). TEAE grade 3-5 adverse were also similar between groups (morphine $72 \%$ vs placebo $83 \%$; online supplementary table S1). More grade 3-5 adverse events occurred during the treatment week in the morphine than in the placebo group $(52.7 \%$ vs $18.1 \%)$, which contributed to differential study withdrawal: (morphine $25.0 \%$ vs placebo $9.6 \%$ ). A larger proportion of TEAE grade 3-5 did not resolve by the end of the follow-up period in the placebo (62.5\%) than morphine group (33.3\%; online supplementary table S1). Participants in the morphine group reported more constipation $(56 \%$ vs $43 \% ; \mathrm{p}=0.037)$ and vomiting ( $37 \%$ vs $23 \% ; \mathrm{p}=0.012$ ). They also reported a greater mean increase from baseline compared with placebo for constipation $(13.47$; $95 \%$ CI 5.31 to 21.62 ; $\mathrm{p}=0.001)$, nausea/vomiting $(7.51 ; 95 \% \mathrm{CI} 1.98$ to 13.04 ; $\mathrm{p}=0.008)$ and fatigue $(10.92 ; 95 \%$ CI 4.78 to $17.06 ; \mathrm{p}<0.001)$ on the EORTC-QLQ-C15 PAL (table 2).

No participants had respiratory depression. There were no statistically nor clinically significant differences between morphine and placebo in mean change from baseline of respiratory rate $(-1.13 \mathrm{bpm} ; 95 \% \mathrm{CI}-2.43$ to $0.18 ; \mathrm{p}=0.089)$, endtidal $\mathrm{CO}_{2}(1.41 \mathrm{~mm} \mathrm{Hg} ; 95 \% \mathrm{CI}-0.28$ to $3.10 ; \mathrm{p}=0.102)$ or pulse oximetry $\left(\mathrm{SpO}_{2}\right)(-1.01 \%$; $95 \% \mathrm{CI}-1.19 \%$ to $0.50 \%$; $\mathrm{p}=0.43$ ). Survival was similar 35 days after first study drug: morphine $84.0 \%$ and placebo $85.5 \%$ (online supplementary table S2).

\section{Subgroup analysis}

Participants with a baseline mMRC of 3 or $4(n=167 ; 59 \%$; the original study population up until July 2014) had similar baseline characteristics (online supplementary table S3) and findings were similar to the whole study population. There were no clinically important differences for any of the primary or secondary endpoints. There was a trend of reduction by morphine in worst breathlessness, mean difference of $-7.81 \mathrm{~mm}(95 \% \mathrm{CI}-14.65$ to -0.97$)$ compared with placebo, and unpleasantness of breathlessness now $(-6.15,95 \% \mathrm{CI}-12.13$ to 0.18$)$, but these findings were not seen for the other breathlessness endpoints (online supplementary table S3).

\section{DISCUSSION}

In people with chronic breathlessness due to a range of conditions, $20 \mathrm{mg}$ oral SR morphine showed no effect on intensity of breathlessness now or any of the secondary endpoints, including intensity of worst, best and average breathlessness, breathlessness unpleasantness, functional status, health-related quality of life in participants and caregivers or participant treatment preference in the intention-to-treat population.

The safety profile was consistent with previous RCTs of lowdose morphine. ${ }^{1322} 23$ SR morphine was well-tolerated with no 
Table 2 Treatment effects of sustained-release morphine $20 \mathrm{mg} /$ day versus placebo from baseline to days $5-7$ or end of treatment in the intentionto-treat population $(n=284)$

\begin{tabular}{|c|c|c|c|c|}
\hline & $\begin{array}{l}\text { Morphine } 20 \mathrm{mg} / \text { day } \\
(\mathrm{n}=145)\end{array}$ & Placebo $(n=139)$ & Morphine versus placebo & \\
\hline & \multicolumn{2}{|c|}{ Mean change from baseline (SE) } & Mean difference $(95 \% \mathrm{Cl})$ & $P$ value \\
\hline \multicolumn{5}{|l|}{ Primary endpoint } \\
\hline Breathlessness now (VAS) & $-5.00(2.13)$ & $-4.86(2.07)$ & $-0.15(-4.59$ to 4.29$)$ & 0.95 \\
\hline \multicolumn{5}{|l|}{ Secondary endpoints } \\
\hline Worst breathlessness, 24 hours (VAS) & $-10.51(2.59)$ & $-5.29(2.61)$ & $-5.23(-10.77$ to 0.31$)$ & 0.064 \\
\hline Best breathlessness, 24 hours (VAS) & $-2.11(2.14)$ & $0.80(2.10)$ & $-2.91(-7.43$ to 1.61$)$ & 0.207 \\
\hline Average breathlessness, 24 hours (VAS) & $-4.49(2.09)$ & $-2.36(2.06)$ & $-2.13(-6.64$ to 2.38$)$ & 0.355 \\
\hline Breathlessness unpleasantness now (VAS) & $-2.16(2.21)$ & $0.10(2.20)$ & $-2.26(-6.87$ to 2.36$)$ & 0.338 \\
\hline Change in participant functional status (AKPS) & $-1.15(0.75)$ & $-0.26(0.75)$ & $-0.89(-2.44$ to 0.66$)$ & 0.260 \\
\hline Participant health-related quality of life (EORTC-QLQ-C15 PAL) & $1.8(2.2)$ & $1.5(2.2)$ & $0.35(-4.41$ to 5.11$)$ & 0.88 \\
\hline Appetite loss (EORTC-QLQ-C15 PAL) & $3.0(3.2)$ & $0.5(3.2)$ & $2.46(-4.22$ to 9.14$)$ & 0.47 \\
\hline Constipation (EORTC-QLQ-C15 PAL) & $15.8(3.8)$ & $2.3(3.8)$ & 13.47 (5.31 to 21.62$)$ & 0.001 \\
\hline Dyspnoea (EORTC-QLQ-C15 PAL) & $-7.0(2.9)$ & $-5.9(2.8)$ & $-1.08(-7.14$ to 4.98$)$ & 0.73 \\
\hline Emotional functioning (EORTC-QLQ-C15 PAL) & $-0.8(2.3)$ & $2.2(2.3)$ & $-3.08(-7.97$ to 1.81$)$ & 0.215 \\
\hline Fatigue (EORTC-QLQ-C15 PAL) & $6.1(2.9)$ & $-4.8(2.9)$ & 10.92 (4.78 to 17.06$)$ & $<0.001$ \\
\hline Nausea/vomiting (EORTC-QLQ-C15 PAL) & $6.1(2.6)$ & $-1.4(2.6)$ & 7.51 (1.98 to 13.04$)$ & 0.008 \\
\hline Pain (EORTC-QLQ-C15 PAL) & $-1.1(2.4)$ & $0.02(2.4)$ & -1.12 (-6.28 to 4.05$)$ & 0.67 \\
\hline Physical functioning (EORTC-QLQ-C15 PAL) & $-5.0(2.3)$ & $-0.6(2.4)$ & $-4.42(-9.43$ to 0.59$)$ & 0.083 \\
\hline Insomnia (EORTC-QLQ-C15 PAL) & $-6.1(3.5)$ & $-8.4(3.4)$ & $2.27(-5.10$ to 9.64$)$ & 0.54 \\
\hline Carers quality of life (CQOLC) & $-1.4(2.3)$ & $-2.4(3.2)$ & $0.94(-7.70$ to 9.58$)$ & 0.82 \\
\hline \multicolumn{5}{|l|}{ Blinded treatment preference } \\
\hline I have been less breathless during the past week & $64 / 132(48.5 \%)$ & $66 / 134(49.3 \%)$ & N/A & N/A \\
\hline This medication would benefit me enough to be on it long term & $55 / 128(43.0 \%)$ & $62 / 131(47.3 \%)$ & N/A & N/A \\
\hline
\end{tabular}

AKPS, Australia-modified Karnofsky Performance Status; CQOLC, Carer Quality of Life Index-Cancer; VAS, $100 \mathrm{~mm}$ visual analogue scale.

episodes of respiratory depression nor serious adverse events. Morphine was associated with increased rates of well-described opioid-related adverse effects of constipation, vomiting, nausea and fatigue. In this relatively large, opioid-naive population with severe illness, there were no hospital admissions for respiratory depression, confusion or obtundation. Observational data on associations between opioid treatment and adverse events have been conflicting. ${ }^{24}$ 37-39 Vozoris et al reported higher rates of hospitalisation and mortality in people with a COPD diagnosis in the community treated with opioids for any reason (with no data on why opioids were commenced nor the doses used). ${ }^{24}$ In contrast, there were no clear associations for admission or death associated with low-dose opioids in people with severe oxygen-dependent COPD ${ }^{22}$ or interstitial lung disease. ${ }^{25}$ Further safety data from randomised and large prospective observational studies are needed to define the rates of more infrequent or longer-term events.

Rescue morphine use was lower in the morphine than the placebo group which could, at least partly, contribute to the lack of difference in endpoints between groups. However, the use was only a mean 0.56 doses (or $1.4 \mathrm{mg}$ ) daily higher in the placebo group which would be unlikely to mask any large treatment effect.

\section{Strengths}

This is the first double-blind, randomised, parallel-group, multicentre, controlled trial of opioids for chronic breathlessness, and the largest study in this field to date. It was rigorously conducted, monitored in accordance with GCP standards and used validated endpoint measures relevant to the participant population.

\section{Limitations}

A limitation was that the inclusion criteria were broadened from mMRC 3-4 to mMRC 2-4 two-thirds the way through the study to facilitate recruitment. Findings in the original target population with mMRC 3-4 was consistent with the main findings, with the addition of a trend for decreased worst breathlessness and unpleasantness of breathlessness now in the morphine arm. However, this trend was not seen across other breathlessness endpoints and might, in the light of the number of endpoints tested, represent a chance finding. This needs validation in further randomised trials. Of note, participant selection was by mMRC, which mainly assesses the functional disability and impact of breathlessness and not the intensity of the symptom itself (the primary endpoint). ${ }^{17} 27 \mathrm{mMRC}$ is widely used for participant stratification in research and is strongly predictive of disease severity and clinical outcomes. ${ }^{940}$ Complementing the mMRC were the baseline measures of chronic breathlessness, demonstrating a significant ongoing burden from the symptom.

A key limitation was the availability of 'as needed' immediaterelease oral morphine to both groups, required by the ethics committee. Both arms will have differences reduced because both arms had exposure to morphine. The differences created are likely to be relatively small given that there were few doses taken in each arm on average. Future studies should be conducted without such rescue medication-an ethically defensible 
Table 3 Treatment emergent adverse events (TEAE) of special interest

\begin{tabular}{|c|c|c|c|}
\hline & \multicolumn{2}{|l|}{ Safety population } \\
\hline & & Morphine $(n=142)$ & Placebo $(n=137)$ \\
\hline \multicolumn{2}{|c|}{$\begin{array}{l}\text { Subjects with at least one special interest } \\
\text { TEAE }\end{array}$} & 129 (90.8\%) & 130 (94.9\%) \\
\hline \multirow{3}{*}{$\begin{array}{l}\text { Any respiratory } \\
\text { disorder }\end{array}$} & & $61(43.0 \%)$ & $71(51.8 \%)$ \\
\hline & Bronchospasm & $56(39.4 \%) \dagger$ & $65(47.4 \%) \dagger$ \\
\hline & Wheezing & $3(2.1 \%)$ & $4(2.9 \%) \dagger$ \\
\hline \multirow{6}{*}{$\begin{array}{l}\text { Any gastrointestinal } \\
\text { disorder }\end{array}$} & & $108(76.1 \%)$ & $94(68.6 \%)$ \\
\hline & $\begin{array}{l}\text { Abdominal pain or } \\
\text { discomfort }\end{array}$ & $10(7.0 \%)$ & $5(3.6 \%)$ \\
\hline & Constipation* & $79(55.6 \%) \dagger$ & $59(43.1 \%) \dagger$ \\
\hline & Dry mouth & $36(25.4 \%)$ & $40(29.2 \%) \dagger$ \\
\hline & Nausea & $6(4.2 \%)$ & $4(2.9 \%)$ \\
\hline & Vomiting** & $53(37.3 \%)$ & $32(23.4 \%) \dagger$ \\
\hline \multirow{4}{*}{$\begin{array}{l}\text { Any cardiac } \\
\text { disorders }\end{array}$} & & $23(16.2 \%)$ & $13(9.5 \%)$ \\
\hline & Arrhythmia & $22(15.5 \%)$ & $13(9.5 \%) \dagger$ \\
\hline & Bradycardia & $2(1.4 \%)$ & $0(0.0 \%)$ \\
\hline & Tachycardia & $1(0.7 \%)$ & $0(0.0 \%)$ \\
\hline \multirow[t]{3}{*}{ Vascular disorders } & & $20(14.1 \%)$ & $23(16.8 \%)$ \\
\hline & Flushing & $7(4.9 \%)$ & $10(7.3 \%)$ \\
\hline & Hypertension & $13(9.2 \%)$ & $16(11.7 \%) \dagger$ \\
\hline \multirow{5}{*}{$\begin{array}{l}\text { Any nervous system } \\
\text { disorder }\end{array}$} & & $105(73.9 \%)$ & $95(69.3 \%)$ \\
\hline & Dizziness & $37(26.1 \%) \dagger$ & $35(25.5 \%) \dagger$ \\
\hline & Headache & $29(20.4 \%) \dagger$ & $27(19.7 \%)$ \\
\hline & Somnolence & $85(59.9 \%) \dagger$ & $70(51.1 \%)$ \\
\hline & Tremor & $26(18.3 \%)$ & $20(14.6 \%)$ \\
\hline \multirow{4}{*}{$\begin{array}{l}\text { Any psychiatric } \\
\text { disorder }\end{array}$} & & $56(39.4 \%)$ & $53(38.7 \%)$ \\
\hline & Agitation & $37(26.1 \%)$ & $38(27.7 \%) \dagger$ \\
\hline & Delirium & $12(8.5 \%) \dagger$ & $10(7.3 \%) \dagger$ \\
\hline & Mood altered & $21(14.8 \%)$ & $21(15.3 \%) \dagger$ \\
\hline \multirow[t]{4}{*}{ Skin disorder } & & $23(16.2 \%)$ & $16(11.7 \%)$ \\
\hline & Rash & $0(0.0 \%)$ & $1(0.7 \%)$ \\
\hline & Rash maculopapular & $0(0.0 \%)$ & $1(0.7 \%)$ \\
\hline & Urticaria & $23(16.2 \%)$ & $15(10.9 \%)$ \\
\hline
\end{tabular}

Data presented as frequency (percentage); ${ }^{*} \mathrm{p}=0.037$ for difference between the groups; ${ }^{* *} p=0.012$ for difference between groups.

†At least one participant experienced this TEAE with NCI-CTCAE severity grade 3, 4 or 5 . The safety population included all participants who received at least one dose of study medication.

NCI-CTCAE, National Institutes of Health Common Terminology Criteria for Adverse Events.

approach. The present findings pertain to people without clinically significant hypercapnia. The study was for 1 week and trials with longer follow-up is needed. The largest prospective, openlabel, dose-ranging study to date did not report evidence of any tachyphylaxis. ${ }^{31}$

\section{Implications for clinical care}

This study did not confirm the reductions in breathlessness seen in previous smaller trials and meta-analyses. ${ }^{15}{ }^{25}$ For the clinician, the present results do not support the use of morphine for chronic breathlessness in people with advanced disease but who are mostly ambulatory, corresponding to the present study population. Given the potentially larger benefit of morphine in patients with worse symptoms, ${ }^{16}$ the present findings need to be validated by further RCTs and especially in patients with more severe and disabling breathlessness. Except for increased rates of constipation and vomiting, which were expected and reversible effects of morphine, the treatment was well-tolerated.

\section{Implications for research}

This study has identified a strong need for a large RCT to define the efficacy, optimal dose and target population of worst breathlessness, and to further evaluate the safety of SR morphine in people with severe chronic breathlessness. ${ }^{41}$ Such a study should comprise standardised non-pharmacological supportive care and should not include any 'as needed' opioid treatment. Understanding the role of dose titration on chronic breathlessness in such a population is an important design feature of this study.

\section{Conclusion}

In patients with optimally treated severe disease and chronic breathlessness (mMRC 2-4), $20 \mathrm{mg}$ oral SR morphine daily was not observed to improve breathlessness now more than placebo, but the intervention arm used fewer doses of 'as needed' morphine. There were no serious adverse events.

\section{Author affiliations}

${ }^{1}$ IMPACCT, Faculty of Heath, University of Technology Sydney, Sydney, New South Wales, Australia

${ }^{2}$ College of Medicine and Public Health, Flinders University, Adelaide, South Australia, Australia

${ }^{3}$ McCloud Consulting Group, Sydney, New South Wales, Australia

${ }^{4}$ Respiratory and Sleep Medicine, Austin Health, Heidelberg, Victoria, Australia

${ }^{5}$ University of Melbourne, Melbourne, Victoria, Australia

${ }^{6}$ Northern Sydney Local Health District, Saint Leonards, New South Wales, Australia ${ }^{7}$ Northern Clinical School, University of Sydney, Sydney, New South Wales, Australia

${ }^{8}$ Deakin Health Economics, Deakin University Faculty of Health, Burwood, Victoria, Australia

${ }^{9}$ Department of Clinical Sciences, Division of Respiratory Medicine \& Allergology, Lund University, Lund, Sweden

Acknowledgements Thanks go to every participant who participated in this study at a very difficult time of their life, and to the families and friends who supported them. Thanks go to the staff at each site, also, for their enduring efforts in working with participants to complete the study. Thanks, also, go to Professor Miriam Johnson for her helpful critique of the manuscript.

Contributors All the authors contributed to the conception, writing and final approval of this manuscript.

Funding Funding was provided for the study by the Australian Government Department of Health through the National Palliative Care Program.

Disclaimer The funder had no control over study design, conduct, analysis, interpretation nor dissemination of results.

Competing interests DCC has unrestricted research grant from Mundipharma, is an unpaid member of an advisory board for Helsinn Pharmaceuticals, and has consulted to Specialist Therapeutics and Mayne Pharma, and received intellectua property payments from Mayne Pharma. All other authors declare no competing interests.

Patient consent for publication Written consent was given for publication of the results.

Ethics approval This study was approved by the Human Research Ethics Committee at each site.

Provenance and peer review Not commissioned; externally peer reviewed.

Data availability statement Data are available on request from bona fide researchers.

ORCID iD

David Currow http://orcid.org/0000-0003-1988-1250 


\section{REFERENCES}

1 Currow DC, Smith J, Davidson PM, et al. Do the trajectories of dyspnea differ in prevalence and intensity by diagnosis at the end of life? A consecutive cohort study. I Pain Symptom Manage 2010;39:680-90.

2 Moens $\mathrm{K}$, Higginson IJ, Harding $\mathrm{R}$, et al. Are there differences in the prevalence of palliative care-related problems in people living with advanced cancer and eight non-cancer conditions? A systematic review. J Pain Symptom Manage 2014;48:660-77.

3 Grønseth R, Vollmer WM, Hardie JA, et al. Predictors of dyspnoea prevalence: results from the BOLD study. Eur Respir J 2014;43:1610-20.

4 Johnson MJ, Yorke J, Hansen-Flaschen J, et al. Towards an expert consensus to delineate a clinical syndrome of chronic breathlessness. Eur Respir J 2017;49:1602277.

5 Smith AK, Currow DC, Abernethy AP, et al. Prevalence and outcomes of breathlessness in older adults: a national population study. J Am Geriatr Soc 2016;64:2035-41.

6 Ho SF, O'Mahony MS, Steward JA, et al. Dyspnoea and quality of life in older people at home. Age Aging 2001;30:155-9.

7 Currow DC, Dal Grande E, Ferreira D, et al. Chronic breathlessness associated with poorer physical and mental health-related quality of life (SF-12) across all adult age groups. Thorax 2017;72:1151-3.

8 Punekar YS, Mullerova H, Small M, et al. Prevalence and burden of dyspnoea among patients with chronic obstructive pulmonary disease in five European countries. Pulm Ther 2016:2:59-72.

9 Nishimura K, Izumi T, Tsukino M, et al. Dyspnea is a better predictor of 5-year survival than airway obstruction in patients with COPD. Chest 2002;121:1434-40.

10 Booth S, Silvester S, Todd C. Breathlessness in cancer and chronic obstructive pulmonary disease: using a qualitative approach to describe the experience of patients and carers. Pall Supp Care 2003;1:337-44.

11 Herzog M, Sucec J, Van Diest I, et al. Observing dyspnoea in others elicits dyspnoea, negative affect and brain responses. Eur Respir J 2018;51:1702682.

12 . Available: https://www.ebs.tga.gov.au/ebs/picmi/picmirepository.nsf/pdf? OpenAgent\&id=CP-2013-PI-01928-1\&d=201903241016933 [Accessed 2019 Mar 23].

13 Jennings A-Let al. A systematic review of the use of opioids in the management of dyspnoea. Thorax 2002:57:939-44.

14 Abernethy APet al. Randomised, double blind, placebo controlled crossover trial of sustained release morphine for the management of refractory dyspnoea. BMJ 2003;327:523-8.

15 Ekström M, Nilsson F, Abernethy AA, et al. Effects of opioids on breathlessness and exercise capacity in chronic obstructive pulmonary disease. A systematic review. Ann Am Thorac Soc 2015;12:1079-92.

16 Johnson MJ, Bland JM, Oxberry SG, et al. Opioids for chronic refractory breathlessness: patient predictors of beneficial response. Eur Respir J 2013:42:758-66.

17 Parshall MB, Schwartzstein RM, Adams L, et al. American Thoracic Society Committee on Dyspnea. An official American Thoracic Society statement: update on the mechanisms, assessment, and management of dyspnea. Am J Respir Crit Care Med 2012;185:435-52.

18 From the global strategy for the diagnosis, management and prevention of COPD, global initiative for chronic obstructive lung disease (GOLD), 2017. Available: http:// goldcopd.org/ [Accessed 8 July 2018].

19 Marciniuk DD, Goodridge D, Hernandez P, et al. Managing dyspnea in patients with advanced chronic obstructive pulmonary disease: a Canadian thoracic Society clinical practice guideline. Can Respir J 2011;18:69-78.

20 Mahler DA, Selecky PA, Harrod CG, et al. American College of chest physicians consensus statement on the management of dyspnea in patients with advanced lung or heart disease. Chest 2010;137:674-91.

21 National Comprehensive Cancer Network (NCCN) Clinical Practice Guidelines in Oncology - Palliative Care. Pal-11 Dyspnea, 2018. Available: https://www.nccn.org/ professionals/physician_gls/pdf/palliative.pdf [Accessed 4 July 2018].
22 Ekström MP, Bornefalk-Hermansson A, Abernethy AP, et al. Safety of benzodiazepines and opioids in very severe respiratory disease: national prospective study. BMJ 2014;348:g445.

23 Verberkt CA, van den Beuken-van Everdingen MHJ, Schols JMGA, et al. Respiratory adverse effects of opioids for breathlessness: a systematic review and meta-analysis. Eur Respir J 2017;50:pii: 1701153.

24 Vozoris NT, Wang X, Fischer HD, et al. Incident opioid drug use and adverse respiratory outcomes among older adults with COPD. Eur Respir J 2016;48:683-93.

25 Bajwah S, Davies JM, Tanash H, et al. Safety of benzodiazepines and opioids in interstitial lung disease: a national prospective study. Eur Respir J 2018;52:1801278.

26 European Medicines Agency. ICH Harmonised tripartite guideline E6: note for guidance on good clinical practice (PMP/ICH/135/95). London: European Medicines Agency, 2002.

27 Bestall JC, Paul EA, Garrod R, et al. Usefulness of the medical Research Council (MRC) dyspnoea scale as a measure of disability in patients with chronic obstructive pulmonary disease. Thorax 1999;54:581-6.

28 Abernethy AP, Shelby-James T, Fazekas BS, et al. The Australia-modified Karnofsky Performance Status (AKPS) scale: a revised scale for contemporary palliative care clinical practice [ISRCTN81117481]. BMC Palliat Care 2005:4:7.

29 Levey AS, Bosch JP, Lewis JB, et al. A more accurate method to estimate glomerular filtration rate from serum creatinine: a new prediction equation. modification of diet in renal disease Study Group. Ann Intern Med 1999;130:461-70.

30 Gourlay. Proceeding of the 7th world Congress on pain: a comparison of Kapanol (a new sustained release morphine formulation). MST Conlinus, and morphine solution in cancer patients: Pharmokinetic aspects of morphine and morphine metabolites. Pain Res Manag 1994;2:631-43.

31 Currow DC, McDonald C, Oaten S, et al. Once-daily opioids for chronic dyspnea: a dose increment and pharmacovigilance study. J Pain Symptom Manage 2011:42:388-99.

32 Aaronson NK, Ahmedzai S, Bergman B, et al. The European organization for research and treatment of cancer QLQ-C30: a quality-of-life instrument for use in international clinical trials in oncology. J Nat/ Cancer Inst 1993;85:365-76.

33 Weitzner MA, Jacobsen PB, Wagner $\mathrm{H}$, et al. The Caregiver Quality of Life IndexCancer (CQOLC) scale: development and validation of an instrument to measure quality of life of the family caregiver of patients with cancer. Qual Life Res 1999;8:55-63.

34 National Cancer Institute. Cancer therapy evaluation program. Common terminology for adverse events V3.0. Available: http://ctep.cancer.gov/protocolDevelopment/ adverse effects.htm [Accessed 7 August 2018].

35 Ekström M, Williams M, Johnson MJ, et al. Agreement Between Breathlessness Severity and Unpleasantness in People With Chronic Breathlessness: A Longitudinal Clinical Study. J Pain Symptom Manage 2019;57:715-23.

36 Johnson MJ, Bland JM, Oxberry SG, et al. Clinically important differences in the intensity of chronic refractory breathlessness. J Pain Symptom Manage 2013;46:957-63

37 Dublin S, Walker RL, Jackson ML, et al. Use of opioids or benzodiazepines and risk of pneumonia in older adults: a population-based case-control study. J Am Geriatr Soc 2011:59:1899-907.

38 Wiese AD, Griffin MR, Schaffner W, et al. Opioid analgesic use and risk for invasive pneumococcal diseases: a nested case-control study. Annals Int Med 2018;168:396-404

39 Edelman EJ, Gordon KS, Crothers K, et al. Association of prescribed opioids with increased risk of community-acquired pneumonia among patients with and without HIV. JAMA Intern Med 2019;179:297-304.

40 Celli BR, Cote CG, Marin JM, et al. The body-mass index, airflow obstruction, dyspnea, and exercise capacity index in chronic obstructive pulmonary disease. N Eng/ J Med 2004:350:1005-12.

41 Currow D, Watts GJ, Johnson M, et al. A pragmatic, phase III, multisite, double-blind, placebo-controlled, parallel-arm, dose increment randomised trial of regular, low-dose extended-release morphine for chronic breathlessness: breathlessness, exertion and morphine sulfate (BEAMS) study protocol. BMJ Open 2017;7:e018100. 
Correction: Regular, sustained-release morphine for chronic breathlessness: a multicentre, double-blind, randomised, placebo-controlled trial

Currow D, Louw S, McCloud P, et al. Regular, sustained-release morphine for chronic breathlessness: a multicentre, double-blind, randomised, placebo-controlled trial. Thorax 2020;75:50-6. doi:10.1136/thoraxjnl-2019-213681.

Since the online publication of this article, the authors have noticed that one of the authors was listed incorrectly as Nikki McCaffery. The correct spelling is Nikki McCaffrey.

(C) Author(s) (or their employer(s)) 2020. No commercial re-use. See rights and permissions. Published by BMJ.

Thorax 2020;75:e5. doi:10.1136/thoraxjnl-2019-213681corr1

A) Check for updates 